\title{
Influence of Vesicular-Arbuscular Mycor- rhizal Fungi on the Nodulation and Growth of Subclover
}

\author{
NORMAN E. GREEN, MICHAEL D. SMITH, WILLIAM D. BEAVIS, AND EARL F. ALDON
}

\begin{abstract}
This study was initiated to determine the influence of vesiculararbuscular mycorrhizal (VAM) fungi on a rhizobium-legume interaction. Inoculation of subclover with Glomus fasciculatus resulted in 2 times as many rhizobium nodules on roots as on nonmycorrhizal controls. Inoculation with Glomus mosseae resulted in 1.4 times greater nodule formation compared to the noninoculated controls. Plants inoculated with $G$. mosseae $+G$. fasciculat us had 1.9 times more nodules than the controls. Furthermore, inoculation with G. fasciculatus or G. mosseae + G. fasciculatus resulted in shoot weights and total plant weights nearly double that of the controls. The conclusion is that inoculation with the correct VAM fungal species is as important as the selection of the rhizobium species for subclover growth and development.
\end{abstract}

The increased demand for energy resources has resulted in large tracts of a rid and semiarid rangelands being disturbed by the quest for coal and oil shale. Both the 1972 federal mining law and state regulations require the reclamation of these lands to acceptable standards for forage and wildlife habitat. Western rangelands are generally deficient in nitrogen and phosphorus throughout their soil profiles; as a result, standard rehabilitation operations must use large applications of these inorganic fertilizers to establish site productivity (Bauer et al. 1978). However, the costs of fertilizer of ten exceed the actual benefits derived from their use in reseeding projects in arid locations. Abbott and Robson studied the growth of subterranean clover inoculated with two types of vesicular arbuscular endophytes and compared them with that of noninoculated plants at 5 levels of applied superphospate in a high phosphate fixing soil. A greater growth response of plants inoculated with a fungus resembling $G$. mosseae was associated with a greater amount of mycorrhizal roots. Responses in nodulation closely paralleled responses in growth.

This study was initiated to determine the potential of using existing biological systems in place of expensive fertilizer applications for site rehabilitation. Legumes will, with associated rhizobium, fix large quantities of nitrogen; this association might be useful as a biological system for supplying nitrogen. However, the legume-rhizobium interaction requires relatively high levels of phosphorus (van Schreven 1958). Since vesicular-arbuscular mycorrhizal (VAM) fungi increase the uptake of phosphorus by their host plants, a study was initiated to determine the influence of VAM fungis on a rhizobium-legume association under low phosphorus conditions. The use of mist chambers for root studies

\footnotetext{
Authors are, respectively, associate professor, graduate research assistant, and former student, Department of Range Management, Humboldt State University, Arcata, California 95521, and project leader, Rocky Mountain Forest and Range Experiment Station, Albuquerque, New Mexico 87106 . William Beavis is presently a research assistant, lowa State University, Ames 50011.

This research was funded by the Rocky Mountain Forest and Range Experiment Station, at the Station's Research Work Unit in Albuquerque, in cooperation with the University of New Mexico. Station headquarters is in Fort Collins, in cooperation with Colorado State University.

Manuscript received December 4, 1981
}

avoids the confounding effects of edaphic factors (Graham et al. 1976).

\section{Materials and Methods}

Spores of Glomus mosseae (Nichol. and Gerd.) Gerdemann and Trappe and Glomus fasciculatus (Thaxter sensu Gerdemann) Gerdemann and Trappe, collected in the state of Washington, were multiplied in pot culture on wheat (Graham et al. 1976). Spores were extracted by wet sieving and decanting (Gerdemann and Nicholson 1963) and stored in Ringer's solution (Daniels and Graham 1976) for about 3-5 months before use.

Seeds of subclover (Trifolium subterranean L. cv. Mount Barker) were surface disinfected in a $0.5 \%$ sodium hypochlorite solution and rinsed 5 times in sterile, distilled water. The moistened seeds were inoculated with a commercial preparation of Rhizobium trifolii (Dungeard) by placing them in the preparation and thoroughly coating each seed. The inoculated seeds were then planted in 3-inch pots containing a 1 to 1 mixture $(\mathrm{vol} / \mathrm{vol})$ of sterile autoclaved sand and vermiculite.

When the seedlings reached the two-leaf stage, they were carefully tapped out of the pots, and the roots were rinsed free of sand and vermiculite with tap water. The seedlings were then placed in 3-inch pots with one root subtended through a 1/2-inch hole drilled in the base of each pot. One to 3 lateral roots were left confined within the pot. The confined roots were covered with 1/2-inch of moistened vermiculite, and the potted plants were then placed in a misted-root culture chamber (Hansen et al. 1979).

The roots were sprayed continuously with a fine mist of a 40 -fold dilution of a modified Hoaglands number 2 solution to allow healing of any abrasions on the roots (Graham et al. 1976). After 7 days, the vermiculite covering the confined roots was carefully rinsed out of the pots with tap water. Roots of the plants used for controls were recovered with moistened vermiculite and placed back on the misted-root chambers. Plants for the VAM fungi treatments were inoculated by placing 10-15 spores of each selected VAM fungal species directly on the rootlets confined within the pot. The inoculated roots were covered with moistened vermiculite, and the pots again placed in the root-chamber and misted with the same diluted Hoglands solutions (available phosphorus maintained at $10^{-6} \mathrm{M}$ concentration). Treatments, in addition to the $R$. trifolii inoculation already done, were (1) control-no VAM inoculation; (2) G. mosseae; (3) G. fasciculatus; (4) G. mosseae + G. fasciculatus-inoculated with 15 spores each of the VAM fungi $G$. mosseae and $G$. fasciculatus. All root lengths were measured every 2 weeks until all of the plants were harvested 12 weeks following inoculation, when the following data were also collected: Number of nodules/ root system, root dry weight, shoot dry weight, and total plant dry weight. Presence of VAM mycelium was determined by trypan blue staining techniques. Two completely randomized blocks of 92 plants/block were used, which represents a total of 23 plants per treatment, replicated twice. 


\section{Results}

Nodule Formation

Nodules and VAM mycelium were observed throughout the root systems both in the vermiculite group mass and in those roots within the chamber.

Inoculation of subclover roots with either species of both species of VAM fungi enhanced nodule formation (Fig. 1). The average number of nodules per plant for each treatment was Control 173.8, G. mosseae 242.9, G. fasciculatus 351.6, and G. mosseae $+G$. fasciculatus 337.9. Inoculation with $G$. fasciculatus resulted in nodule formation that was 2.0 times greater than that of the control. Plants inoculated with $G$. mosseae had the lowest number of nodules formed for any of the mycorrhizae treatments, but nodule formation was 1.4 times greater than that of the controls. (The 1.4 requires additional testing to check its validity.) Combining $G$. mosseae and $G$. fasciculatus as an inoculum resulted in slightly fewer nodules than the $G$. fasciculatus treatment (1.9 times greater than that of the control). Microscopic inspection indicated presence of VAM in all mycorrhizal treatments, but percent infection was not quantified. In the $G$. mosseae $+G$. fasciculatus treatment infections was determined, but identification by species was not possible.

\section{Plant Growth}

Plants inoculated with either species or both species of VAM fungi had greater shoot and total weights than the controls (Table 1). The largest shoot weights and total plant weights were obtained from either the $G$. fasciculatus or the G. mosseae $+G$. fasciculatus treatments. Although none of the treatments produced significantly greater root weights, the $G$. fasciculatus treatment and, to a lesser extent, the G. mossea + G. fasciculatus treatment did produce somewhat greater root weights than either the $G$. mosseae treatment or the control. The G. mosseae inoculated plants had the lowest root weights of any of the VAM treatments. Root lengths

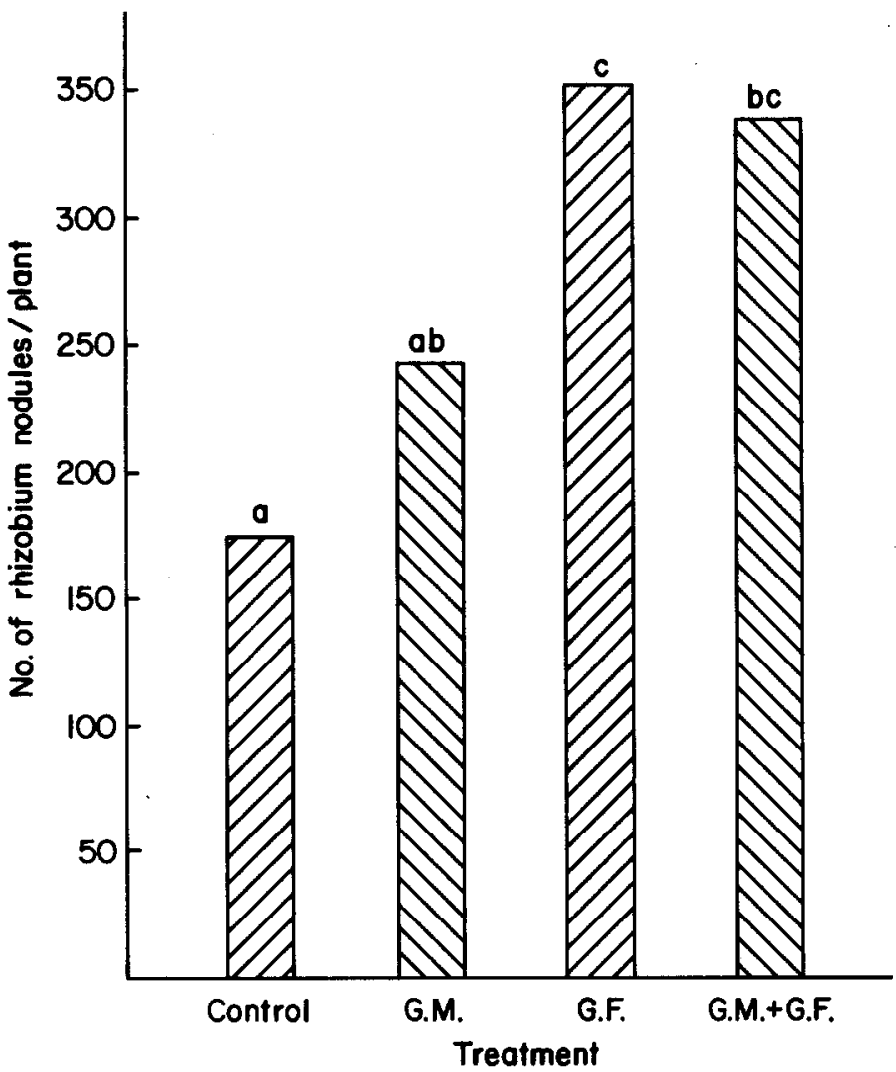

Fig. 1. The influence of the vesicular-arbuscular mycorrhizal fungi Glomus mosseae $(G M)$ and $\mathrm{G}$. fasciculatus $(G F)$ on Rhizobium trifolii nodule formation on the roots of subclovers grown in mist culture. Treatments followed by a different letter are significantly different $(\mathrm{P}<0.05)$.
Table 1. Influence of VAM fungi on the growth of Rhizobium trifolit inoculated subclover grown in misted-root chambers.

\begin{tabular}{lccc}
\hline \hline & \multicolumn{3}{c}{ Average dry weight/plant (g)' } \\
\cline { 2 - 4 } Treatment & Roots & Shoots & Total \\
\hline Control & $0.02 \mathrm{a}$ & $0.44 \mathrm{a}$ & $0.64 \mathrm{a}$ \\
Glomus mosseae & $0.20 \mathrm{a}$ & $0.71 \mathrm{ab}$ & $0.91 \mathrm{ab}$ \\
G. fasciculatus & $0.28 \mathrm{a}$ & $0.83 \mathrm{~b}$ & $1.11 \mathrm{~b}$ \\
G. mosseae + G. fasciculatus & $0.24 \mathrm{a}$ & $0.89 \mathrm{~b}$ & $1.13 \mathrm{~b}$ \\
\hline
\end{tabular}

'Means within columns followed by a different letter are significantly different $(P<0.05)$.

were significantly greater for the G. fasciculatus and the G. mosseae $+G$. fasciculatus treatments than for the control at 12 weeks (Fig. 2). However, the differences in root length were slow to levelop. For the first 8 weeks following inoculation, root lengths were essentially the same for the various treatments. From 8 weeks to 12 weeks after inoculation, there was a gradually increasing root length difference between the $G$. fasciculatus and $G$. mosseae $+G$. fasciculatus treatments compared to the control (Fig. 2).

\section{Discussion}

The results of this experiment show that inoculation with the VAM fungus $G$. fasciculatus greatly increases the number of rhizobium nodules formed on subclover roots. It also greatly increases shoot growth and, thus, total plant growth. The increase in nodule formation could be due to the increased phosphorus uptake by the clover as a result of the VAM infection (Mosse 1973) (Cress 1979). Phosphorus is requisite for good rhizobium nodule formation (van Schreven 1958). Further studies are needed to elucidate the cause of the nodule stimulation by $G$. fasciculatus. The results of this study support the concept that VAM fungi are essential for the growth of legumes in phosphorus-deficient soils, as proposed by Asai (1948), Baylis (1961), and Possingham et al. (1971). The increases in plant growth because of VAM inoculation are similar to those reported by Crush (1974) and O'Bannon et al. (1980) for other legumes. Furthermore, these results show that there is a specificity between subclover and the species of VAM fungus with which it is inoculated as evidenced by the stimulation effect of $G$. fasciculatus and the near neutral effect of $G$. mosseae. The apparent lack of difference in the results obtained using $G$. fasciculatus

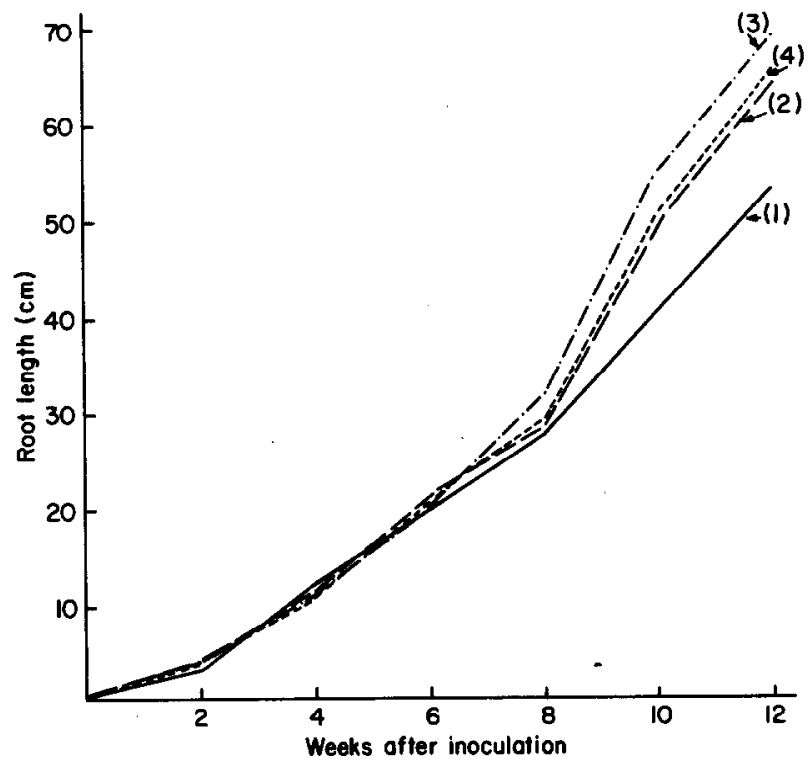

Fig. 2. The influence of VAM fungi on root length of Rhizobium trifolii inoculated subclover grown in misted-root chambers. $V A M$ treatments were (1) control; (2) Glomus mosseae; (3) G. fasciculatus; (4) G. mosseae $+\mathbf{G}$. fasciculatus. 
compared with $G$. mosseae $+G$. fasciculatus suggests that there is a possibility those spores from $G$. fasciculatus were the only ones or at least the predominant ones to infect the plants of the combination treatment. This implication suggests that future host specificity studies should incorporate infectivity measurements. It is also possible that changes in subclover varieties, soil $\mathrm{pH}$, soil moisture, and/or soil temperature could change the interactions with the VAM species. These results indicate that the selection of the VAM species is as important to subclover success as the selection of the rhizobium species. These findings show that, with the correct species of VAM, subclover has a greater potential foliage production, which would provide increased forage for grazing livestock following the reclamation project.

\section{Literature Cited}

Abbott, L.K., and A.D. Robson. 1977. Growth stimulation of subterranean clover with vesicular abuscular mycorrhizas. Aust. J. Heric. Res. 28:639-649.

Asai, T. 1948. Uber die mykorrhizendildung der leguminosen pflanzea. Jap. J. Bot. 13:463-485.

Baylis, G.T.S. 1961. The significance of mycorrhizae and root nodules in New Zealand vegetation. Roy. Soc. N.S. Proc. 89:45-50.

Bauer, Armand, William A. Berg, and Walter L. Gould. 1978. Correction of nutrient deficiencies and toxicities in strip-mined land in semi-arid and arid regions. Chap. $25 \mathrm{In}$ : Reclamation of Drastically Disturbed Lands, Amer. Soc. Agronomy. Madison, Wisc.

Dean of the College of Agriculture, The University of Wyoming. Applications and nominations are invited for the position of Dean of the College of Agriculture, Director of the Agricultural Experiment Station and Agricultural Extension Service. The Dean is chief academic and administrative officer for the College of Agriculture and directs operation of both the Wyoming Agricultural Experiment Station and Agricultural Extension Service. The position holds responsibility for budgeting human, physical and financial resources, including state and federal funds, as well as providing effective leadership in teaching, research, extension and service programs. Qualifications for the position include an earned doctorate, a record of academic excellence, demonstrated administrative leadership, a firm commitment to the interdependence of research, teaching, extension and service in a land grant university and an ability to communicate effectively with faculty, staff, students, and external agricultural constituents. Salary will be commensurate with ability and experience and competitive nationally. Nominations and applications, including a resume, other supporting material and five references, will be accepted until January 15, 1984, and should be addressed to: Dr. Don A. Roth, Chairman, Search Committee for the Dean of the Agriculture College, The University of Wyoming, Box 3354, University Station, Laramie, Wyoming 82071 . The University of Wyoming is an Equal Opportunity, Affirmative Action Employer.
Cress, William A., Glyn O. Throneberry, and Donald Lindsey. 1979. Kinetics of phosphorus absorption by mycorrhizal and nonmycorrhizal tomatoe roots. Plant Physiol. 64:484-487.

Crush, J.R. 1974. Plant growth responses to vesicular-arbuscular mycorrhiza. VII. Growth and nodulation of some herbage legumes. New Phytol. 73:743-749.

Daniels, B.A., and S.O. Graham. 1976. Effects of nutrition and soil extracts on germination of Glomus mosseae spores. Mycologia 68:108-116.

Gerdemann, J.W., and T.H. Nicholson. 1963. Spores of mycorrhizal Endogone species extracted from soil by wet sieving and decanting. Trans. Brit. Mycol. Soc. 46:235-244.

Graham, S.O., N.E. Green, and J.W. Hendrix. 1976. The influence of vesicular-arbuscular mycorrhizal fungi on growth and tuberization of potatoes. Mycologia 68:925-929.

Hansen, C.A., N.E. Green, and E.F. Aldon. 1979. Misted-root chambers: A technique for studying the physiology and morphology of roots. Proc. Ann. Meetings SRM 32:26(Abst.)

Mosse, B. 1973. Advances in the study of vesicular-arbuscular mycorrhiza. Ann. Rev. Phytopathol. 11:171-196.

O'Bannon, J.H., D.W. Evans, and R.N. Peaden. 1980. Alfalfa varietal response to seven isolates of vesicular-arbuscular mycorrhizal fungi. Can. J. Plant Sci. 60:859-863.

Possingham, J.V., J.G. Obblink, and R.K. Jones. 1971. Tropical legumes and vesicular-arbuscular mycorrhiza. J. Anst. Inst. Agr. Sci. 37:160-161.

van Schreven, D.A. 1958. Some factors affecting uptake of nitrogen by legumes. In: Nutrition of legumes (E.G. Hallsworth ed.) p. 137-148. Buttersworth, London.

U.S. DEPARTMENT OF AGRICULTURE, Fort Keogh Livestock and Range Research Laboratory, Miles City, Montana, is seeking a Supervisory Research Animal Scientist to serve as Laboratory Director to develop and conduct a research program in range beef cattle nutrition, and coordinate the overall research programs of the 55,000 acre station. Applicants must be U.S. citizens and have knowlege of range beef cattle nutrition, and animal genetics and physiology. Salary range: $\$ 41,277-\$ 48,553$. For qualification and application information contact Rita Millard, Personnel Staffing Specialist, USDA, Oakland, CA, on (415)273-4281 by November 25, 1983. AN EQUAL OPPORTUNITY EMPLOYER.

\section{TWO WILDLIFE FACULTY POSITIONS}

Assistant Professor of Wildlife Management: The Department of Range and Wildlife Management at Texas Tech University seeks to fill two teaching/research positions. One position will be filled on January 1, 1984, and other position will be filled on July 15, 1984. Teaching responsibilities for each position will include some combination of Big Game Ecology, Upland Game Ecology, Wild life Techniques, Wildlife Population and Dynamics, Wildlife Physiological Ecology, and Introductory Wildlife. Please indicate your strengths and preferences in a resume. Each faculty member will have 3 or 4 courses to teach per year. A diversity of research interests and backgrounds adaptable to West Texas will be considered. Send resume, transcripts, and a statement of teaching and research interests, and three letters of reference to: Dr. Henry A. Wright, Chairperson, Department of Range and Wildlife Management, P.O. Box 4169, Texas Tech University, Lubbock, Texas 79409. Review of applications for the January position will be December 1 , 1983 and review of applications for the July position will be April 1, 1984. Texas Tech University is an affirmative action/ equal opportunity employer. 